\title{
Functional Associations of "Trouble Seeing"
}

\author{
Raynard Kington, MD, PhD, Jeanette Rogowski, PhD, Lee Lillard, PhD, \\ Paul P. Lee, MD, JD
}

\begin{abstract}
The purpose of this study was to determine how vision problems affect health status. The information was collected in 1990 from 2,249 household heads and spouses over 50 years of age during an annual survey of a nationally representative sample that was adjusted for attrition and nonresponse. Vision problems were defined as "trouble seeing (even with glasses or contact lenses)." Health status was measured principally with the Medical Outcomes Study Short-Form 36. Regression analyses found a significant relationship between "trouble seeing" and each of five health-status domains. We conclude that it may not be appropriate to require specific functional limitations as a precondition for cataract surgery and that instruments for measuring functional disabilities related to vision should include more general questions.
\end{abstract}

KEY WORDS: vision; trouble seeing; functional status. J GEN INTERN MED 1997;12:125-128.

D ifficulties with vision have profound effects on mortality, vision-specific and general functional status, activities of daily living, and overall quality of life. ${ }^{1-6}$ However, few studies have examined the relation between visual symptoms or complaints and functional and health status, especially relative to other symptoms or medical conditions. ${ }^{7-9}$ This report examines the relation between self-reported "trouble seeing (even with glasses or contact lenses)," six other symptoms, and nine general disease conditions with five different measures of health status.

\section{METHODS}

\section{Study Sample}

The Panel Study of Income Dynamics is a national probability longitudinal survey of households. ${ }^{10}$ Household

Received from RAND, Santa Monica, Calif., and Washington, DC (RK, JR, LL, PPL), Department of Medicine, UCLA School of Medicine (RK), and Doheny Eye Institute, University of Southern California School of Medicine, Los Angeles (PPL).

Presented in part at the National Eye Institute, March 1993, and the American Academy of Ophthalmology annual meeting, Chicago, Ill., November 1993.

Address correspondence and reprint requests to Dr. Lee: 1450 San Pablo St., Los Angeles, CA 90033. heads of approximately 5,000 original families have been interviewed annually since 1968 concerning family characteristics such as income, employment, education, and demographic changes, with oversampling for those families whose income is less than twice the poverty level.

In 1990, all household heads and spouses over 50 years of age were asked to complete detailed health questionnaires. Of 3,277 eligible individuals, 2,429 (74\%) returned questionnaires. The analyses presented here use techniques designed to reflect the original 1968 sampling, corrections for attrition, and adjustments for nonresponse. ${ }^{11}$

\section{Health and Functional Status Measures}

The 1990 health questionnaire included previously tested questions on five domains of health status: (1) general health perceptions; (2) physical role functioning; (3) emotional role functioning; (4) physical functioning; and (5) mental health. The questions are from the Medical Outcomes Study Short-Form 36, ${ }^{12}$ except for the physical functioning questions, which were derived from the National Long Term Care Survey Screener. ${ }^{13}$ The questions, scoring procedures, and range for each scale are in Appendix A and Table 1. Scale scores were transformed to scores from 0 to 100 in Table 2.

The health questionnaire also included seven symptoms and nine general groups of diseases: "trouble seeing (even with glasses or contacts)" found in $20 \%$ of the population; paralysis or neurological problems $(5 \%)$; angina (8\%); back problems $(28 \%)$; deafness (14\%); incontinence (13\%); trouble with thinking, concentration, or memory (20\%); heart failure (9\%); asthma or severe lung problem (11\%); ulcers (10\%); chronic inflamed bowel (6\%); allergies (33\%); kidney disease (5\%); diabetes mellitus (12\%); hypertension (38\%); and arthritis (32\%). A tenth disease group, amputation of arm or leg, occurred in less than $1 \%$ of the sample; inclusion or exclusion did not significantly alter the results.

\section{Analysis Plan}

Multivariate analyses were conducted using all 16 symptoms and conditions and six demographic variables (age, race, gender, educational status, marital status, and household income) to determine their relative, unique associations with each of the scales. All analyses were con- 
Table 1. Health Status Outcome Scales*

\begin{tabular}{|c|c|c|}
\hline Scale & $\begin{array}{l}\text { Potential Range } \\
\text { of Scores }\end{array}$ & $\begin{array}{c}\text { Sample Mean Score, } \\
\text { Unconverted }( \pm S D)\end{array}$ \\
\hline $\begin{array}{l}\text { General health } \\
\text { perception }\end{array}$ & $5-25$ & $17.7( \pm 4.8)$ \\
\hline $\begin{array}{l}\text { Physical } \\
\text { functioning }\end{array}$ & $0-15$ & $12.8( \pm 4.6)$ \\
\hline $\begin{array}{l}\text { General mental } \\
\text { health }\end{array}$ & $0-25$ & $19.5( \pm 4.8)$ \\
\hline $\begin{array}{l}\text { Physical role } \\
\text { functioning }\end{array}$ & $0-3$ & $2.1( \pm 1.2)$ \\
\hline $\begin{array}{l}\text { Emotional role } \\
\text { functioning }\end{array}$ & $0-3$ & $2.7( \pm 0.8)$ \\
\hline
\end{tabular}

*Higher scores signify better health. See Appendix A for items making up each scale.

ducted using ordinary least squares regression; in addition, ordered logistic regressions were performed for categorical scoring of the physical and emotional role functioning scales.

\section{RESULTS}

Of the 2,429 respondents, $41 \%$ (994) were male. Seventy-two percent $(1,747)$ were white, $24 \%$ black, and $4 \%$ other ethnicities. Those aged 50 to 64 years constituted $54 \%$, while $29 \%$ were aged 65 to 74 years and $17 \%$ were 75 or older. Sixty-three percent were married, $23 \%$ widowed, $11 \%$ divorced or separated, and 3\% never married.

Table 2 presents the transformed, weighted scale means, standard deviations, and the weighted ordinary least squares regression coefficients for the five health status scales. Results did not differ for the emotional and physical role function scales when logistic regression was performed; for ease of presentation, the linear regression results are provided. Only age, incontinence, and trouble seeing were significantly associated with differences in all five outcome measures. Education, paralysis, angina, cognition problems, and chronic obstructive pulmonary disease (COPD)/asthma were related to four of the scales. For all five scales, the presence of medical conditions or symptoms was related to a poorer health state, with the exceptions of allergies and deafness.

Table 2. Regression Coefficients Describing How Demographic Factors and the Presence of Symptoms and Disease Were Related to Scores on the Health Status Scales*

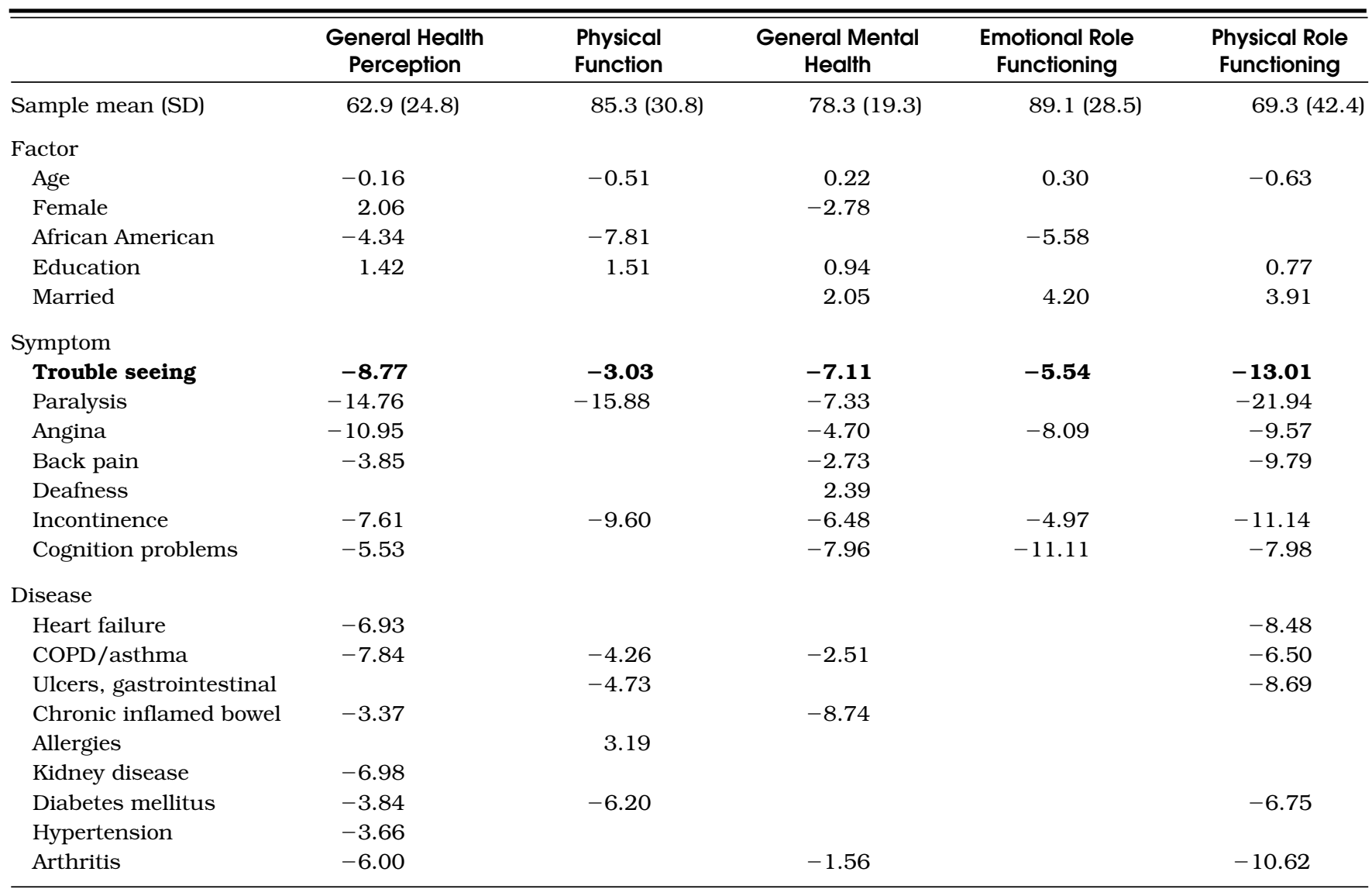

*Each scale is scored from zero (worst) to 100 (best). A negative coefficient indicates that the demographic factor, symptom, or disease was associated with a worsening health status. Only those coefficients that were statistically significant at a p-value less than or equal to .05 are presented; a blank indicates the coefficient was not significant. 


\section{DISCUSSION}

This study demonstrates the significant adverse functional relation between self-reported "trouble seeing" and health status in the aged, general population of the United States. Unlike studies limited to specific populations or locations, or to those who actually receive care, this study uses a national probability sample corrected for nonresponse and attrition. However, this study is limited by the lack of information in the questionnaire as to diagnoses or the severity of trouble seeing; as such, no additional specific linkages can be drawn.

The first important implication of this finding is that difficulty with specific activities may not be justified as a sole precondition for receiving eye care, such as cataract surgery. For example, current instruments for measuring vision-related functional limitations due to cataract enumerate specific activities. ${ }^{14-17}$ The RAND/Academic Medical Center Consortium criteria for measuring the appropriateness of cataract surgery and the Agency for Health Care Policy and Research (AHCPR)-sponsored guideline for cataract management also require the presence of specific, identifiable functional difficulties as a precondition for cataract surgery. ${ }^{17}$ This study suggests that such requirements should be reassessed because even a general symptom of "trouble seeing" is associated with important functional status decrements. The importance of this point has been emphasized by results from the AHCPR Patient Outcome Research Team project on cataract surgery demonstrating that cataract symptoms had an independent role in determining patient satisfaction. ${ }^{9}$

A second implication is that future instruments for measuring functional disabilities related to vision should consider the inclusion of more general questions. Although the exact nature of such questions needs further investigation, such questions should be evaluated for use in generic vision-related functioning and health status questionnaires.

Finally, this and similar studies have begun to expand the understanding of the value of vision relative to other capacities by comparing the effects of varying symptoms and conditions on common functioning and health status end points. Such findings indicate the need to understand not only the nature of the measures but also how various deficits in skills or functions relate to one another. ${ }^{8}$ By understanding the impact of a symptom or disease, and measuring the mitigating effect of available interventions (if any), a rudimentary approach to determining "benefit" to supplement ongoing utility or satisfaction considerations can be made. In an era of scarce re- sources, such understanding may serve to better direct allocation of resources.

\section{REFERENCES}

1. LaForge RG, Spector WD, Sternberg J. The relationship of vision and hearing impairment to one-year mortality and functional decline. J Aging Health Care. 1992;4:126-48.

2. Branch LG, Horowitz A, Carr C. The implications for everyday life of incident self-reported visual decline among people over age 65 living in the community. Gerontologist. 1989;29:359-65.

3. Kosnik W, Winslow L, Kline D, Rasinski K, Sekuler R. Visual changes in daily life throughout adulthood. $J$ Gerontol. 1988;43:P63-70.

4. Scott IU, Schein OD, West S, et al. Functional status and quality of life measurement among ophthalmic patients. Arch Ophthalmol. 1994;112:329-35.

5. Brenner MH, Curbow B, Javitt JC, et al. Vision change and quality of life in the elderly. Arch Ophthalmol. 1993;111:680-5.

6. Salive ME, Guralnik J, Blynn RJ, et al. Association of visual impairment with mobility and visual function. J Am Geriatr Soc. 1994;42:287-92.

7. Brenner MH, Curbow B, Legro MW. The proximal-distal continuum of multiple health outcome measures: the case of cataract surgery. Med Care. 1995;33:AS236-44.

8. Carabellese C, Appollonio I, Rozzini R, et al. Sensory impairment and quality of life in a community elderly population. J Am Geriatr Soc. 1993;41:401-7.

9. Steinberg EP, Tielsch JM, Schein OD, et al. National study of cataract surgery outcomes: variation in 4-month postoperative outcomes as reflected in multiple outcome measures. Ophthalmology. 1994;101:1131-41.

10. Hill MS. The Panel Study of Income Dynamics: A User's Guide. Newbury Park, Calif: Sage Publications; 1992.

11. Morgan JN. A Panel Study of Income Dynamics Procedures and Tape Codes 1988 Interviewing Year Wave XXI: A Supplement, Vol 1. Ann Arbor, Mich: Survey Research Center; 1991.

12. Stewart AL, Hays RD, Ware JE. The MOS Short Form General Health Survey: reliability and validity in a patient population. Med Care. 1988;26:724.

13. U.S. Department of Health and Human Services. National Longterm care survey, 1982-1984. Volumes 1 and 2, 3rd ed. Washington, DC. 1984.

14. Javitt JC, Brenner MH, Curbow B, et al. Outcomes of cataract surgery: improvement in visual acuity and subjective visual function after surgery in the first, second, and both eyes. Arch Ophthalmol. 1993;111:686-91.

15. Mangione CM, Phillips RS, Seddon J, et al. Development of the "activities of daily vision scale": a measure of visual functional status. Med Care. 1992;30:1111-26.

16. Sloane ME, Ball K, Owsley C, Bruni JR, Roenker DL. The visual activities questionnaire: developing an instrument for assessing problems in everyday visual tasks. Technical Digest. 1992;1:21-9.

17. Lee P, Kamberg C, Hilborne L, et al. Cataract surgery: a review of the literature and ratings of appropriateness and cruciality. Santa Monica, Calif: RAND; 1993. Publication JRA-06. 


\section{APPENDIX A}

\section{Health Status Multi-item Subscales: Questions and Scoring}

For each subscale, a higher score indicates better health.

I. General Health Perceptions Questions

1. In general, would you say your health is: excellent $=5.0$, very good $=4.4$, good $=3.4$, fair $=2.0$, poor $=1.0$

Scoring for questions 2 and 3: definitely true $=1$, mostly true $=2$, don't know $=3$, mostly false $=4$, definitely false $=5$

2. I seem to get sick a little easier than other people.

3. I expect my health to get worse.

Scoring for questions 4 and 5 : definitely true $=5$, mostly true $=4$, don't know $=3$, mostly false $=2$, definitely false $=1$ 4. I am as healthy as anybody I know.

5. My health is excellent.

General health perceptions subscale $=$ sum score

questions 1-5 (range 5-25). Cronbach $\alpha=0.8631$.

II. Physical Role Functioning

Scoring for questions 1-3: yes $=0$, no $=1$

1. Over the past month, have you cut down on the amount of time at work or other activities as a result of your physical health?

2. Over the past month, have you accomplished less as a result of your physical health?

3. Over the past month, have you had difficulty performing work or other activities as a result of your physical health?

Physical role functioning subscale $=$ sum score questions

1-3 (rang 0-3). Cronbach $\alpha=0.9065$.

III. Emotional Role Functioning

Scoring for questions 1-3: yes $=0$, no $=1$

1. Over the past month, have you cut down on the amount of time at work or other activities as a result of your emotional health?

2. Over the past month, have you accomplished less as a result of your emotional health?

3. Over the past month, were you to do work or other activities as carefully as usual as a result of your emotional health?

Emotional role functioning subscale $=$ sum score questions 1-3 (range 0-3). Cronbach $\alpha=0.9001$.

IV. Physical Functioning Questions

Scoring for questions $1-5$ : yes $=0$, no $=1$

Does your health limit you in each of the following activities?
A. Instrumental activities of daily living

1. Preparing meals without help.

2. Doing laundry without help.

3. Doing light housework, such as washing dishes.

4. Shopping for groceries without help.

5. Managing money, such as keeping track of bills and handling cash.

6. Taking medicine without help.

7. Making telephone calls without help.

B. Activities of daily living

8. Eating without the help of another person or equipment.

9. Getting in or out of bed without help.

10. Getting in or out of chairs without help.

11. Dressing without help.

12. Walking around inside without help.

13. Going outside without the help of another person or special equipment.

14. Bathing without help.

15. Getting to the bathroom or using the toilet.

Physical functioning subscale $=$ sum score 1-15 (range 0-15).

Cronbach $\alpha=0.9772$.

V. Mental Health Questions

Scoring for questions 1-3: all of the time $=0$, most of the time $=1$, a good bit of the time $=2$, some of the time $=3$, a little of the time $=4$, none of the time $=5$.

1. How much of the time, during the past month, have you been a very nervous person?

2. During the past month, how much of the time have you felt downhearted and blue?

3. How often during the past month, have you felt so down in the dumps that nothing could cheer you up?

Scoring for questions 4 and 5 : all of the time $=5$, most of the time $=4$, a good bit of the time $=3$, some of the time $=2$, a little of the time $=1$, none of the time $=0$.

4. During the past month, how much of the time have you felt calm and peaceful?

5. During the past month, how much of the time have you been a happy person?

Mental health subscale $=$ sum score questions $1-5$ (range 0-25). Cronbach $\alpha=0.8668$. 